\title{
A Metonymical Approach to Anaphora in English Texts
}

\author{
Qiang Zhang ${ }^{1}$ \\ ${ }^{1}$ School of Foreign Languages, Shandong Jiaotong University, Jinan 250023, China \\ Correspondence: Qiang Zhang, 5001 Haitang Road, Jinan, Shaodong Province, 250023, China. Tel: \\ 86-186-6017-6618. E-mail: 170983040@qq.com
}

Received: May 13, 2014

Accepted: May 28, 2014

Online Published: June 10, 2014

doi:10.5430/elr.v3n1p58

URL: http://dx.doi.org/10.5430/elr.v3n1p58

\begin{abstract}
Due to the fast development of cognitive linguistics, which makes the perspective of anaphoric studies become more abundant, we may propose a cognitive framework for metonymy in order to make analysis of anaphora in English texts. In this paper, the author is going to apply the theory of metonymy to the explanation of anaphora in English texts. First the author proposes the metonymic mechanism of NP anaphora, pronominal anaphora and zero anaphora in English texts. Then the author makes metonymical interpretation of these three kinds of anaphora by means of analyzing some typical examples. And the author reckons that the metonymic approach to anaphora could be regarded as a complement of the cognitive angle of view of anaphora.
\end{abstract}

Keywords: Anaphora, Metonymy, Metonymical relationships, Textual cohesion

\section{Introduction}

Anaphora is a concept that one linguistic presentation (always in abbreviated form) usually stands for another expression (always come out in the previous text and sometimes appear in the subsequent text) in the same language text. The former one is termed as anaphor and the latter is termed as antecedent. So anaphora is a kind of language phenomenon that can maintain the relationships between anaphor and its antecedent.

It is noteworthy that a lot of scholars do have profound contributions to the researches on phenomena of anaphora and that their achievements will function as the basis of what we are concerning with in this paper. Metonymy is of vital significance and usage to the cohesion and coherence of texts. The author's discussion on metonymy as a textual cohesive device is based on the framework which was proposed by Halliday and Hasan (1976). We practically form a new interpretation and approach to the topic from other perspectives. We may conclude that the cohesive devices which was proposed by Halliday and Hasan can be regarded as the metonymic relationships that can be contributed to the texture of discourse and make the text as an integrated whole. Anaphora is considered to be a kind of "reference" in the framework created by Halliday and Hasan, and could thus be seen from a metonymic perspective. Moreover, the author makes a hypothesis: if metonymy is referential essentially (Lakoff and Johnson 1980; Lakoff 1987; Stallard 1993; Gibbs 1994; Nunberg 1995; Warren 2002), it would make us understand more about reference (consists of anaphora) in texts.

Based on the framework of metonymic theories by Radden and Kovecses (1999), according to Al-Sharafi's (2004) viewpoints on textual metonymy, we construct a "textual model of metonymy" to analyze the effect of metonymy on constructing anaphora and the explanatory power of metonymy on NP anaphora, pronominal anaphora and zero anaphora so as to further the study on anaphora. The author constructs metonymic mechanisms for each of the three kinds of anaphora respectively and exemplifies all of them step by step. This paper intends to demonstrate that the metonymic model in the Idealized Cognitive Model (ICM) and the salience principle can explain NP anaphora and that the metonymic relationships in the textual model of metonymy have some explanatory power for pronominal anaphora and zero anaphora. This paper will not only be a complement to anaphoric researches, but it will also be helpful for text interpreters to get a better understanding of textual cohesion and coherence in English texts.

\section{Literature Review}

Many scholars have made researches on anaphora from syntactic perspective. Foreign linguists Chomsky (1981, 1982) and Aoun (1985) are the most outstanding two that make great contribution to the research. In the binding theory, control theory and empty category theory by Chomsky, he all mentions anaphora and proposes a method of analysis and analyzes anaphora from syntactic level. As Levinson (1987) holds, in the past five years, anaphora has 
played an important role in GB (government-binding) theory. Another scholar Aoun (1985) focuses on the research of anaphora and constructs a grammar of anaphora, indicating that grammar is a symmetric theory of anaphora. Then Huang Yan (1991), who carries out researches on Chinese empty category, also studies anaphora from syntactic perspective.

Furthermore, Levinson (1987) discusses the grammar of anaphora from pragmatic perspective in his article Pragmatic and Grammar of Anaphora: A Partial Reduction of the Binding and Control Phenomenon, and applies Q (quantity)-principle, I (informativeness)-principle and $\mathrm{M}$ (manner)-principle to interpret anaphoric expressions. What is more, Huang Yan $(1991,1994)$ develops a pragmatic theory of anaphora. In his research, he mentions disjoint reference presumption principle. Actually, to some extent, all the viewpoints presented above are concrete developments of Reinhart's research. Among these, the most concrete and feasible one to account for anaphora is the theory by Levinson, which is not suitable for all the anaphoric phenomena, though.

As we know, cognitive linguistics is rapidly developing in the recent two decades. Many linguists study anaphora from the cognitive perspective. Ariel (1990) proposes accessibility theory, which is constructed on human's cognitive regularity. She researches anaphora according to people's accessibility to the expressions presented. She indicates the factors that influence accessibility, classifies referring expressions into low accessibility markers, intermediate accessibility markers and high accessibility markers, and states that actual accessibility making systems are to some extent language-specific; the more informative, rigid (unambiguous), and unattenuated the marker, the lower the accessibility it is specialized for, and vice versa (Ariel 1990: 29). Hoek $(1992,1995)$ makes a research on pronominal anaphora under the framework of cognitive-semantics. She not only researches the restrictions of anaphora, but also puts the previous data of different categories into the cognitive semantic framework and discusses them. She also makes researches on anaphora and explores the continuum of conceptual connectivity, focusing on additional aspects of reference point organization, in her book Anaphora and Conceptual Structure.

\section{Metonymic Mechanism of Anaphora in English Texts}

According to the criterion of anaphor, there are three kinds of anaphora-NP anaphora, pronominal anaphora and zero anaphora. On account of the differences among the anaphors of the three kind of anaphora, we should bear in mind that different metonymic mechanisms could be used to interpret them. Moreover, in this paper, what we are actually analyzing is the indirect anaphora in Quirk et al.'s (1985) words; it is because that metonymic relation may consist in the indirect but not in direct anaphora. We will assign these anaphoric phenomena into respective framework.

\subsection{Metonymic Mechanism of NP Anaphora}

NP anaphora itself has a distinguishing feature: there are two NPs in it. Therefore, NP anaphora is the relationship within two NPs. It is important to note that in our analysis, the relation between anaphor and its antecedent in NP anaphora is not direct or implicit as we interpret it from the perspective of metonymy. Hence, we are going to confine the analysis to a feasible range.

It is known to all, Lakoff (1987: 68) put forward the theory of ICM. He defined an ICM as a "complex structured whole, a gestalt," which adopts four kinds of principles for structuring:

(a) prepositional structure, as in Fillmore's frames;

(b) image-schematic structure, as in Langacker's cognitive grammar;

(c) metaphoric mappings, as described by Lakoff and Johnson;

(d) metonymic mappings, as describe by Lakoff and Johnson.

Each ICM, as used, structures a mental space as described by Fauconnier.

In the above structuring principles, the principle which is most relevant to our discussion is what relates to "metonymic mappings". Lakoff had interpreted the concept of ICM using a model of metonymy (in which the name of places substitutes institutions in examples like "Washington does not say anything".). He claimed that an ICM may play a role of allowing a salient example to substitute an overall category metonymically.

Furthermore, the ICM theory mainly refers to two perspectives: on the one hand, metonymy may emerge where there is an ICM; on the other hand, some conceptual entities in the ICM may bring our attention into focus. Alac and Coulson (2004) proposed that the cognitive principle of relative salience can provide motivation for various metonymies. This salience principle is attached with great importance for metonymic mechanism of NP anaphora, in which only one factor in the model of metonymy could practically represent and hereafter indicate the whole model 
or any other factor within the model, and thus offers texture when anaphora in texts is being processed. Let's see the following example:

(1) We arrived in a village. The church was closed.

In the above anaphora, we could infer an ICM which is "a village". When referring to the concept of village, there might be shops, streets, churches, etc. So, there may be a close relation (which can be called part-whole) between "the church" (anaphor) and "a village" (antecedent). We often use memorable or otherwise salient instances to understand the categories. Hence, we may conclude that "the church" is more salient in our ICM of village by explaining the relationship of part and whole metonymically between the anaphor and its antecedent.

In conclusion, we could assume that the concept of ICM proposed by Lakoff (1987) and the salience principle can explain the NP anaphora in this paper.

\subsection{Metonymic Mechanism of Pronominal Anaphora}

In this section, the author is to discuss personal pronoun anaphora in its restrictive sense referring to pronominal anaphora. In discourse analysis, we often pay our attention to the third person pronoun when studying on the personal pronoun. It is because that the usages of the first and second person pronoun always rely on the circumstances and can be distinguished in an easy way, while the usage of third person pronoun is more complicated. We can acquire the features of pronominal anaphora quite easily, because its anaphor is a pronoun, especially the third person pronoun.

Stallard (1993) and Nunberg (1995) have put forward a theory of metonymy saying that it is a referential phenomenon. They proposed that metonymy could explain the phenomena of indirect anaphora. Al-Sharifi (2004: 112) had proposed an example of this indirect anaphora:

(2) A: The cabinet decided in Favor of an increase in petrol process yesterday.

\section{B: They anticipated a lot of protest from the people, though.}

In the example above, we can conclude that this is a pronominal anaphora, and it can also be regarded as an indirect anaphora. The word "they" is the pronoun which refers to a singular inanimate antecedent. The resolution to the question is offered by a metonymic explanation of the overall interchange in which "the cabinet" is practically a surface NP representing an underlying NP: the government officials in the cabinet, with which the pronoun "they" naturally agrees. Not only this instance, to a certain degree, but also other examples demonstrate that pronominal anaphora is metonymic, in the sense that there is a procedure of replacement in referencing and a procedure of representation in replacement. As we use a pronoun, we use it to represent a particular noun. Both of the noun and pronoun are practically the forms of a discourse. So there is a stand-for relationship at stake. And this is a basic procedure of metonymic explanation in which one form represents another form.

In particular, we offer a more comprehensive application of metonymy and assert that a relationship of FROM FOR $F R O M$ is a vital metonymic relationship. We could claim that the pronominal anaphora in texts is metonymic of this type. In the following example, we need to demonstrate the relationship associating "Safin" to "he":

(3) Safin endured a nightmare visit to Wimbledon in 2004. He got a first round loss there.

While for the identification of anaphor and the apparent unconformity between the factors of the cohesive bond-pronominal anaphora, let's see the following example:

(4) The beefsteak did not leave any tip because she was angry at the restaurant environment.

The regular interpretation of text connectivity is always confined to the representation that the noun phrase "the beefsteak" is associated with the pronoun "she", which is inadequate. By metonymic inference, we may have the ability to interpret the unconformity and thus becoming to know the phrase "the beefsteak" is the person who has ordered the beefsteak.

From examples (2) to (4), we may learn that the pronominal anaphoric phenomena we are studying in this paper have a precondition that the metonymic relationship exists between the anaphor and its antecedent.

In a word, we assume that metonymy could interpret a lot of pronominal anaphoric phenomena if there is a metonymic operation. We would like to adopt the metonymic text model to analyze pronominal anaphora in English texts. 


\subsection{Metonymic Mechanism of Zero Anaphora}

It is turn out to be true that zero anaphora is scarce in English; however, it could often be seen in Chinese texts. The evident feature of zero anaphora is that it has only an antecedent and bears no anaphor. Therefore, a "zero-form" exists in the anaphora. Baker (1992) argued that pronouns are scarcely used and, in case of a participator is introduced, the consistency of reference would be marked by omission of the subjects of following clauses. On this condition, a zero anaphora could be actually some kind of omission. Thereafter, it is the concept of the identification of the participator which is regained; an event is put down to that subject. As the same, the CONCEPT FOR FORM which is the metonymy-producing relation operates under this circumstance.

See the following example:

(5) Billy went to the supermarket, and bought some bananas.

It is generally acknowledged that zero anaphora bears an indirect property. Therefore, metonymy may be considered to be able to explain zero anaphora. In the example (5), the anaphor is in the zero form while the antecedent could be retrieved in an easy way. Thus, we can conclude that the anaphor is an implied concept that can represent "Billy", which is the practical form, due to our metonymic way of thinking. In order to clarify it, a metonymic relation is operating in the zero anaphora mentioned above. As such, we may assume that the metonymic relationships in the textual framework of metonymy could be adopted to analyze zero anaphora.

In this part, the author tries to put forward the metonymical mechanisms for anaphora in English texts. On account of their separate imparities, we make an assumption that NP anaphora could be explained by metonymy in the theoretical framework of ICM and the principle of saliency; pronominal anaphora and zero anaphora could be accounted for by the metonymy-generating relationships under the textual framework of metonymy.

\section{Metonymic Interpretation of Anaphora in English Texts}

Anaphora is a crucial grammatical device of textual cohesion. From the discussion in the above part, we get to know that metonymy could explain the pronominal anaphora, NP anaphora and zero anaphora. Anaphora could be conveyed as a phenomenon that reduces the sphere of modes, concepts and objects, not only of textual anaphora, to which it is cut in the model put forward by Halliday and Hasan (1976), which regards "anaphora" as the language phenomenon in which particular points of language refer to other things for the explanation.

As for NP anaphora, we are inclined to interpret it with the theory of ICM and the principle of saliency.

\subsection{Metonymic Interpretation of NP Anaphora in English Texts}

The framework of theory for NP anaphora proposes that a metonymy includes a function (or mapping) from one factor to the other "within a single domain structured by an ICM [an Idealized Cognitive Model]" (Lakoff 1987: 288).

It is important to note that two NPs in NP anaphora are considered to be in a same ICM via many metonymical concepts or relationships which is in accordance with persons' metonymical way of thinking. Consider the following instance proposed by Hoey (1991:37) that can expound the point:

(6) A drug known to produce violent reactions in humans has been used for sedating grizzly bears Ursus arctos in Montana, USA, according to a report in the New York Time. After one bear, known to be a peaceable animal, killed and ate a camper in an unproved attack. Scientists discovered it had been tranquillized 11 times with phencyclidine, or "angel dust", which causes hallucination and sometimes gives the user an irrational feeling of destructive power. Many wild bears have become "garbage junkies" feeding from dumps around human developments. To avoid potentially dangerous clashes between them and humans, scientists are trying to rehabilitate the animals' areas. Although some biologists deny that the mind-altering drug was responsible for the uncharacteristic behavior of this particular bear, no research has been done to the effects of giving grizzly bears or other mammals repeated doses of phencyclidine.

In the example above, we can find out two sets of NP anaphora; one group goes with the line of human-scientists-biologists; another group goes with bears-wild bears-animals-mammals. Figure 1 could demonstrate the superordinacy-hyponymy relationship much more evidently. In fact, the hyponym-superordinate relationships can be considered as metonymical relationships, because Radden and Kovecses (1999) have proposed the category-member ICM. Metonymy makes us able to conceptualize a superordinate when the language parts are involved, even though it does not appear in the text. The concept of a superordinate is a useful and important device when analyzing and interpreting the text if it is interpreted in a metonymical way, such as anaphora. 


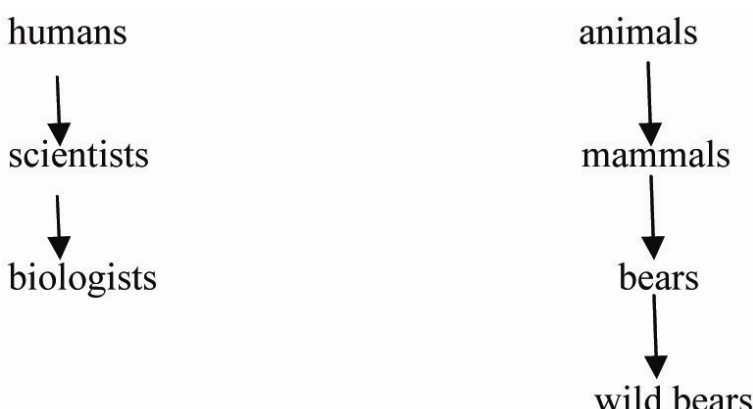

Figure 1

We believe that every group of NP anaphora in text actually establishes an ICM. For example, the prior anaphora constructs an ICM indicating human, and it is composed of scientists, writers and so on; and the ICM of scientists includes biologists, astronomers and so on; furthermore, in the anaphora of human-scientists, we believe that the characteristics of "scientists" is a significant modeling of the overall scope of "human" in line with the language circumstance in the language text, because these features are relevant in a metonymical way as hyponym and superordinate. As such, the anaphor "biologists" is supposed to substitute the metonymical relationship of hyponym and superordinate with the antecedent "scientists". With the theory of ICM and saliency principle, we are able to understand NP anaphora from a new angle of view.

\subsection{Metonymic Interpretation of Pronominal Anaphora in English Texts}

\subsubsection{Nunberg's Explanation}

Nunberg (1995) have proposed that we must make a clear division between postponed reference and predicate transfer. He claimed as soon as the noun is extended, the antecedent of an anaphora factor should be the inexplicit factor.

(7) This is parked out back and it will not start (extended noun: inexplicit antecedent).

But when the predicate is transmitted, the antecedent of anaphora factor has to become the inexplicit factor.

(8) The man with the cigar is parked out back and he might be an hour (transferred predicate: explicit antecedent).

In the above example, the anaphor "it" in example (7) is in fact the intended deep indicator: the car, while the anaphor "he" in example (8) is the superficial NP "the man with the cigar". Nunberg had clarified the way and the reason for accomplishing the mental transaction included in predicate transfer.

\subsubsection{Warren's Interpretation}

Warren's (2002) interpretations were enlightened under the framework of constructive grammar. He has proposed that what we regard to be the theme of a discourse would be the antecedent of an anaphoric pronoun and the salient element of a metonymical presentation, despite its modifying function, could serve as the topic, due to the possible reason that it is in the topic status. As we can see in the following instance:

(9) The kettle [the water] is boiling and it is hot.

What can I tell you about "the kettle"?-Well, the water in it is boiling just now.

In this example we could know that Warren's interpretation is that the inexplicit factor is often a portion of the nominal subject and the shift of reference is allowable but alternation of topic is not.

Moreover, Radden and Kovecses (1999) proposed that the option of the pronoun should be controlled by a common cognitive rule in accordance with which human-beings acquire privilege over non-human-beings. This kind of rule would explain the case that the human entity in the framework looks to be highlighted irrelevant of whether it is the anchor point or the aim. Radden and Kovecses put forward the instance as follows:

(10) a. My ex-husband is parked on the upper deck. It has a California license plate.

b. My ex-husband is parked on the upper deck. He is taking the bus today.

It turns out to be more reasonable and satisfactory intuitively, whereas, to look at the metonymy in sentence $a$ in the example (10) as an example of referential transfer, in other words, to perceive "my ex-husband" in the meaning of the ex-husband's car. Anyway, we prefer to consider it to be the pronominal anaphora in sentence $b$ due to the principle 
of human over non-human. In a word, there are different elements which can decide the option of anaphoric pronouns in metonymical presentations.

\subsection{Metonymic Interpretation of Zero Anaphora in English Texts}

In English language there are few expressions of zero anaphora in discourses. It is remarkable that zero anaphora has an indirect or deep feature, which might include a metonymical relationship. The most prominent characteristic of zero anaphora is that it is in short of anaphor. Thus, zero anaphora is indeed a kind of ellipsis. Therefore, it is the notion of the identification of the participator which is recovered every time an action or an issue is put down to that subject. In the same way it is the metonymical relationship CONCEPT FOR FORM in the text mode of metonymy that operates. According to theory of metonymy proposed by Ullmann's (1962), we could conclude that metonymy, as a representative relationship of CONCEPT FOR FORM, in which a vacant slot represents a mode that is mentioned previously, is essentially on the basis of spatio-temporal contiguity.

The target in this part is to carry out the metonymical representative relationship of CONCEPT FOR FORM to account for zero anaphora in English discourse. As is mentioned above, to some degree, zero anaphora could be considered as a kind of omission, as Halliday and Hasan (1976: 142) claimed it as "substitution by zero". The explanation of all texts includes a lot of "deduction" in which we acquire a great deal of information from the text, as in the following expression:

We are referring specially to sentences, clauses and so on whose structure is such as to presuppose some preceding item, which then serves as the source of the missing information. (Halliday and Hasan 1976: 143)

So the idea holds that the anaphor "zero form" forms a slot in the structure of a text. Let's see an example:

(11) This is parked out back and may not start.

The zero anaphora in example (11) is illustrated and mirrored on the zero form prior to the predicate "may not start" and "this". It is obvious that the intentional citation is not the superficial demonstratum but the implicit indicator "the vehicle" as the supplementary information combined is basically an account of a vehicle. Hence, "this" metonymically represents the vehicle, since only "the vehicle" could possess the predicate "start", but not "this". The zero form virtually stands for the notion of "the vehicle", which represents the actually form in the text mode of metonymy. Therefore the metonymical relationship CONCEPT FOR FORM operates in the zero anaphora.

The case of zero anaphora could be illustrated from the perspective metonymy is also a reflexion in the data of examples. Due to the scarce presence of zero anaphora in English texts, we try to choose the anaphoric phenomena which are not often seen from the data. Let's see the instance:

(12) Saddam Hussein likes munching nacho chips, which is his favorite food; plays a mean game of ping-gong and thinks Ronald Reagan is $O K$.

In (12), the valid references prior to "plays" and "thinks" are both "Saddam Hussein", and it is the antecedent in the zero anaphora, despite the fact that they acts as zero forms in English text. We could conclude some differences between examples (11) and (12): there is a metonymical operation included in (11) but not involved in (12). In fact, we could adopt the metonymy-producing relationship CONCEPT FOR FORM to analyze the two instances. The implied factor is equivalent of a notion which has its own distinct form like the antecedent in zero anaphora.

Moreover, in some descriptive texts, zero anaphoric phenomena are expressed. Consider the following example which describes the fact that a factory worker with no formal higher education is today one of the foremost scholars on the ancient city walls of Nanking:

(13) A few years ago Yang Guoqing was working in a factory in the same job he had been doing for 28 years. Yang is believed to be the first to have completed an overall study of Nanking's Ming Dynasty (1368-1644) city walls. He has published books and papers of nearly 400,000 words on them, and $\varnothing$ is the chief complier of the first encyclopedia of Nanking's historic city walls and Ø helped develop a museum, the first of its kind in China, on them.

We discover that there are several pairs of zero anaphora existing in the above text. We are to select "Yang" as the antecedent and the zero forms before "is" and "helped" the anaphors. These two groups of zero anaphora with the same antecedent hold two zero forms which stand for "Yang Guoqing" in the previous text by our metonymic reasoning. Therefore, the concept that is expressed by zero form stands for the real from. The metonymic relation CONCEPT FOR FORM supports our argument here. 
All the instances above make us understand that under the perspective of metonymy, the zero anaphora could be analyzed and the metonymical representative relationship is apparently in operation in the presentation of zero anaphora to render consistency for the text using the metonymy-producing relationship CONCEPT FOR FORM.

\section{Conclusion}

This paper proposes an analysis of anaphora in English texts from a metonymical perspective. Anaphora could often be seen in English texts and could be regarded as a language link between the anaphor and its antecedent. By analyzing NP anaphora, pronominal anaphora and zero anaphora in English texts, this paper progresses a metonymical method, in other words, the theory of ICM and saliency tenet are applied to NP anaphora; with regard to pronominal anaphora and zero anaphora, the text model of metonymy, particularly the metonymical relationships in the model are adopted.

Admittedly, there are some limitations of the research in this paper. First, the categorization of anaphora in this paper is quite limited and not very explicit to some degree. In fact, the anaphora the author has discussed in this paper belongs to indirect and deep anaphora. So there might be some confusion for us to adopt the categorization. Second, the analysis is restricted to the phenomena of anaphor when there is a metonymical operation. Therefore, the analysis of anaphora without a metonymical operation is still left to be tested.

It was illustrated that pronominal and zero anaphora could be analyzed by means of metonymical text model with the relationships like FORM FOR FORM, CONCEPT FOR FORM, and so on. At the same time, we are curious whether we could analyze NP anaphora that could be depicted by the theory of ICM, though, using the above relationships. Due to the fact that many kinds relationships between the anaphor and its antecedent in NP anaphora, for example, meronymy, hyponymy, synonymy, and so on, there will be difficulty in analyzing all the relationships in integration by metonymical relationships in the textual model.

\section{References}

Alac, M \& Coulson, S. (2004). The Man, the Key, or the Car: Who or What Is Parked out Back? Cognitive Science Online, Vol: (2): 21-34.

Al-Sharifi, A. G. M. (2004). Textual Metonymy: A Semiotic Approach. Houndmills, Basingstoke, Hampshire and NY: Palgrave Macmillan.

Aoun, J. (1985). A Grammar of Anaphor. Cambridge, MA: MIT Press.

Ariel, M. (1990). Accessing Noun-Phrase Antecedent. London: Routledge.

Baker, M. (1992). In Other Words: A Course Book on Translation. London: Routledge.

Barcelona, A. (2000). Metaphor and Metonymy at the Cross Roads: A Cognitive Perspective. Berlin: Mouton de Gruyter.

Carter, D. (1987). Interpreting Anaphora in Natural Language Texts. Chichester: Ellis Horwood,.

Chomsky, N. (1981). Lectures on Government and Binding. Dordrecht: Foris.

Chomsky, N. (1982). Some Concepts and Consequences of the Theory of Government and Binding. Cambridge, MA: MIT Press.

Chu, C. C. (1998). A Discourse Grammar of Mandarine Chinese. NY: Peter Lang.

Cornish, F. (1986) Anaphoric Relations in English and French: A Discourse Perspective. London: Croom Helm.

Croft, W. (1993). The Role of Domains in the Interpretation of Metaphors and Metonymies. Cognitive Linguistics, Vol: (4): 335-370. http://dx.doi.org/10.1515/9783110219197.161

Crystal, D. (1997). A Dictionary of Linguistics and Phonology. Oxford: Blackwell.

Dane, F. (1974). Functional Sentence Perspective and the Organization of the Text. In F. Danes (ed.). Papers on Functional Sentence Perspective. Mouton: Publishing House of the Czechoslovak Academy.

Driven, R. (1999). Conversation as a Conceptual Metonymy of Event Schemata. In K-U, Panther and G Radden (eds.). Metonymy in Language and Thought. Amsterdam/Philadelphia: John Benjamins Publishing Company, pp: 275-289.

Fox, B. (1996). Studies in Anaphora. Amsterdam: John Benjamins Publishing Company Philadelphia.

Garham, A. (2001) Mental Models and the Interpretation of Anaphora. Hove, East Sussex: Psychology Press. 
Gernsbacher, M. A. (1991). Comprehending Conceptual Anaphors. Language and Cognitive Processes, Vol: (6): 81-105. http://dx.doi.org/10.1080/01690969108406939

Gibbs, R. W. Jr. (1994). The Poetics of Mind: Figurative Thought, Language, and Understanding. Cambridge: Cambridge University Press.

Givon, T. (1983). Topic Continuity in Discourse: Quantitative Cross-Linguistic Studies. Amsterdam: John Benjamins Publishing Company.

Goossens, L. (1990). Metaphtonymy: The Interaction of Metaphor and Metonymy in Expressions for Linguistic Action. Cognitive Linguistics, Vol: (1): 323-340. http://dx.doi.org/10.1515/cogl.1990.1.3.323

Grice, H. P. (1975). Logic and conversation. In P. Cole and J. Morgan (eds.). Syntax and Semantics: Volume 3, Speech Acts. New York: Academic Press. pp: 41-58.

Halliday, M. A. K. \& Hasan, R. (1976). Cohesion in English. London: Longman.

Hoey, M. (1991). Patterns of lexis in text. Oxford University Press.

Huang, Y (1994). The Syntax and Pragmatics of Anaphora: A Study with Special Reference to Chinese. Cambridge: Cambridge University Press.

Jakendoff, R. Mme. (1992). Tussaud Meets the Binding Theory. Natural Language and Linguistic Theory. Vol: (8): 1-31. http://dx.doi.org/10.1007/BF00135357

Kempson, R. M. (1984). Pragmatics, Anaphora, and Logic Form. In D. Schiffrin (ed.). Meaning, Form, and Use in Context: Linguistic Applications. Washington, D. C.: Georgetown University Press. pp: 11-42.

Langacker, R. W. (1987). Foundations of Cognitive Grammar. (Vol.1: Theoretical prerequisites). Stanford/California Stanford University Press.

Langacker, R. W. (1996). Conceptual Grouping and Pronominal Anaphora. In F. Barbara (ed.). Studies on Anaphora. Amsterdam/Philadelphia: John Benjamins Publishing Company. http://dx.doi.org/10.1075/tsl.33.11lan

Nunberg, G. (1995). Transfers of Meaning. Journal of Semantics, Vol: (12): 109-132. http://dx.doi.org/10.1093/jos/12.2.109

Panther, K.-U. and Thornburg, L. (1997). Speech Act Metonymies. In W.-A. Liebert, G Redeker, and L. Waugh (eds.). Discourse and Perspectives in Cognitive Linguistics. Amsterdam and Philadelphia: John Benjamins Publishing Company. pp: 205-219.

Panther, K-U. and Thornburg, L. (2004). The Role of Conceptual Metonymy in Meaning Construction. De Metaphorik, Vol: (6): 100-112.

Quirk, R. et al. (1985). A Comprehensive Grammar of the English Language. London: Longman.

Reinhart, T. (1983). Anaphora and Semantic Interpretation. London: Croom Helm.

Ruiz de Mendoza, F. (2000). The Role of Mappings and Domains in Understanding Metonymy. In A: Barcelona (ed.). Metaphor and Metonymy at the Cross Roads: A Cognitive Perspective. Berlin: Mouton de Gruyter. http://dx.doi.org/10.1515/9783110894677.109

Stallard, D. (1993). Two Kinds of Metonymy. In Proceedings of the Annual Meeting of the Association for Computational Linguistics (ACL'93). Columbus: Ohio State University, pp: 87-94. http://dx.doi.org/10.3115/981574.981586

Taylor, J. R. (1989). Linguistic Categorization: Prototypes in Linguistic Theory. Oxford: Oxford University Press.

Thompson, S. A. and Haiman, J. (1988). Clause Combining in Grammar and Discourse. Amsterdam: John Benjamins Publishing Company.

Ullmann, S. (1962). Semantics: An Introduction to the Science of Meaning. Oxford: Basil Blackwell.

Van Hoek. K. (1992) Paths Through Conceptual Structure: Constraints on Pronominal Anaphora. Ph.D. Dissertation. San Diego: University of California.

Warren, B. (2002). An Alternative Account of the Interpretation of Referential Metonymy and Metaphor. In Driven Rene and Porings, Ralf (eds.). Metaphor and Metonymy in Comparison and Contrast. Berlin/New York: Mouton de Gruyter. pp: 113-130. http://dx.doi.org/10.1515/9783110219197.113

Wasow, T. (1979). Anaphora in Generative Grammar. Ghent: E. Story-Scientia. 